\title{
Thermal properties of polyurethane-based composites modified with chitosan for biomedical applications
}

\author{
Monika Szlachta $^{1} \cdot$ Klaudia Ordon $^{1} \cdot$ Katarzyna Nowicka $^{1} \cdot$ Kinga Pielichowska $^{1}[$
}

Received: 23 January 2019 / Accepted: 3 January 2020 / Published online: 21 January 2020

(c) The Author(s) 2020

\begin{abstract}
The thermal properties of chitosan and hydroxyapatite (HAp)-crosslinked polyurethanes (PU) prepared in a two-step bulk polymerization were investigated. Synthesis of PU was carried out using 1,6-hexamethylene diisocyanate, poly(ethylene glycol) 2000 and dibutyltin dilaurate as a catalyst. Various molar ratios of chitosan and 1,4-butanediol were applied, and the effects of incorporating different HAp amounts and the chitosan-to-BDO ratio were studied. It was found that the thermal properties of PU materials depend on polysaccharides and bioceramics load, which was confirmed by differential scanning calorimetry and thermogravimetry. The glass transition temperature increases with increasing chitosan fraction. Similarly, the onset temperature of degradation increased with chitosan addition. On the other hand, the presence of ceramics did not show a significant impact on the thermal properties of PU composites. Successful polymerization and chain extension of the isocyanate groups with hydroxyl moieties from chitosan and HAp were confirmed by Fourier transform infrared spectroscopy, and the morphology was examined using scanning electron microscopy.
\end{abstract}

Keywords Polyurethanes $\cdot$ Chitosan $\cdot$ Hydroxyapatite $\cdot$ Thermal properties

\section{Introduction}

Polyurethane (PU) synthesis involves a step-growth polyaddition reaction between diisocyanate and polyol, where isocyanate group $(-\mathrm{NCO})$ reacts with a hydroxyl group $(-\mathrm{OH})$ and forms a urethane bond [1, 2]. For the synthesis of PU, different types of long chain polyols, such as polyesters, polycarbonates and polyethers, can be used. The second main compounds of PU are aromatic or aliphatic diisocyanates [3]. The characteristic feature of PU is a segmental structure comprised of hard and soft segments. The hard segments are built from diisocyanates and short chain extenders, whereas soft segments are derived from polyols $[4,5]$. Another interesting feature is the microphase separation of hard and soft segments that significantly influence the properties of PU [6]. Typical chain extenders in PU synthesis are low-molecular-weight diols (HO-R-OH), such

Kinga Pielichowska

kingapie@agh.edu.pl

1 Department of Biomaterials and Composites, Faculty of Materials Science and Ceramics, AGH University of Science and Technology, Al. Mickiewicza 30, 30-059 Kraków, Poland as 1,4-butanediol, diethylene glycol, ethylene glycol and 1,6-hexanediol, or diamines $\left(\mathrm{NH}_{2}-\mathrm{R}-\mathrm{NH}_{2}\right)$, like 1,6-hexamethylenediamine and 1,2-ethylenediamine [2,7]. The introduction of chitosan to the polymer matrix as a chain extender/crosslinker is an attractive synthetic route for biomaterials as this polysaccharide enhances the growth of osteoblasts in materials for bone tissue engineering $[8,9]$.

The incorporation of chitosan into the PU matrix as a chain extender is also seen in the literature, especially as a component of the hard segment enhancing the material biocompatibility. For example, Zia et al. [10] used poly( $\varepsilon$ caprolactone) (PCL) and aromatic 2,4-toluene diisocyanate (TDI) to obtain prepolymers extended in the next step with 1,4-butanediol (BDO) and chitosan with different molar ratios. Along with biocompatibility and non-toxicity, chitosan can improve the thermal properties of PUs. A novel approach was described for PU synthesis involving chitosan combined with curcumin as a chain extender, to achieve elastomers for biomedical applications. The authors employed hydroxyl-terminated polybutadiene (HTPB) and 1,6-hexamethylene diisocyanate (HDI) and found that samples with lower contents of chitosan and higher contents of curcumin exhibited improved the thermal stability and tensile strength [11]. Mahanta et al. [12] grafted chitosan with diisocyanate 
terminated PU for controlled drug delivery. Barikani et al. [13] obtained chitosan-based water dispersions of PUs based on PCL and isophorone diisocyanate (IPDI), crosslinked with different mass ratios of chitosan and amines. Interestingly, the thermal stability and contact angle increased with increasing chitosan content. In other work, PU obtained by the reaction of PCL and IPDI and crosslinked with different mass ratios of chitosan and BDO was studied [14]. The incorporation of chitosan into the PU backbone improved the thermal stability of PU. Additionally, the best thermal properties were found for PU extended with chitosan.

To obtain three-dimensional bone scaffolds, HAp/ chitosan-based composites were prepared via a protocol in which the water dispersion of HAp was mixed with chitosan/ $\mathrm{N}$-acetylated chitosan to create $3 \mathrm{D}$ porous scaffolds. The mechanical study of these scaffolds showed an increase in Young's modulus, which is explained by homogeneous dispersion of HAp and the formation of hydrogen bonding between polymer chains and HAp [15]. As HAp exhibits outstanding biocompatibility and bioactivity with hard tissues, it makes an excellent candidate for orthopaedic and dental implants or components of implants and it has been widely used in orthopaedics, especially for bone repair, bone augmentation, implant coating or acting as a filler in bone or teeth $[16,17]$. Due to the presence of $\mathrm{OH}$ groups in the chemical structure of HAp, it is possible to obtain hybrid inorganic-organic systems with different polymers using diisocyanates as coupling agents [18].

In this work, we report on the synthesis and thermal properties of PU bone cement composed of hexamethylene diisocyanate (HDI) and poly(ethylene glycol) (PEG), crosslinked with chitosan and HAp. The effect of different molar ratios of crosslinkers on the thermal properties of PU composite materials was examined by differential scanning calorimetry and thermogravimetry.

\section{Experimental}

\section{Materials}

PEG with a 2000 average molar mass, HDI, BDO and dibutyltin dilaurate (DBTDL) were purchased from SigmaAldrich. Chitosan with a 100,000-300,000 average molar mass was supplied by ACROS Organics. HAp needle-like nanopowder was purchased from mkNano (Canada). Before synthesis, PEG was dried at $80{ }^{\circ} \mathrm{C}$ under vacuum for $2 \mathrm{~h}$, and chitosan and hydroxyapatite were dried at $120{ }^{\circ} \mathrm{C}$ for $24 \mathrm{~h}$.

\section{Synthesis method}

PEG was placed in a three-neck flask, heated to $50{ }^{\circ} \mathrm{C}$ under dry nitrogen. The temperature of the reaction flask was maintained using a heating mantle. In the next step, DBTDL catalyst was added dropwise to the melted PEG and, then, HDI was added. The reaction was carried out at $60{ }^{\circ} \mathrm{C}$ under nitrogen for $1 \mathrm{~h}$. The urethane prepolymers obtained were crosslinked with BDO and/or chitosan with different molar ratios. In addition, HAp in a variable quantity was introduced. The samples were cured at $80{ }^{\circ} \mathrm{C}$ in a dryer for $24 \mathrm{~h}$. The composition of the obtained sample materials is presented in Table 1 .

\section{Techniques}

The morphology and chemical composition studies on the obtained materials were performed using a scanning electron microscope (SEM) (FEI Nova NanoSEM 200) operating at $5 \mathrm{kV}$ and supplied with an energy dispersive $\mathrm{X}$-ray analyser (EDAX Company). The samples were coated with carbon before SEM observation.

The FTIR spectra were recorded using a Bruker Vertex $70 \mathrm{~V}$ Spectroscope with $4 \mathrm{~cm}^{-1}$ resolution and 64 scans in the $4000-500 \mathrm{~cm}^{-1}$ wavenumber range. During the measurement, an attenuated total reflectance (ATR) attachment was applied with diamond crystal.

The effect of chitosan and HAp incorporation into the PU matrix on the thermal stability of composites was investigated using thermogravimetry (TG). TG analysis of PU samples was performed using a Discovery TGA 550 (TA Instruments) thermal analyser in the $20-600{ }^{\circ} \mathrm{C}$ temperature range, at a $10 \mathrm{~K} \mathrm{~min}^{-1}$ heating rate in a nitrogen atmosphere with a ca. $13 \mathrm{mg}$ sample mass. The gas flow was $20 \mathrm{~mL} \mathrm{~min}^{-1}$.

The thermal properties of the PU crosslinked with chitosan and HAp were analysed using a differential scanning calorimeter (DSC1 from Mettler Toledo). The measurements were conducted within the range from -85 to $225^{\circ} \mathrm{C}$ under a $30 \mathrm{~mL} \mathrm{~min}^{-1}$ nitrogen gas flow. The glass transition temperature $\left(T_{\mathrm{g}}\right)$, heat capacity $\left(C_{\mathrm{p}}\right)$, melting temperature $\left(T_{\mathrm{m}}\right)$ and enthalpy of fusion $\left(\Delta H_{\mathrm{m}}\right)$ were determined using STARe

Table 1 Composition of PU/chitosan/HAp samples

\begin{tabular}{llllll}
\hline $\begin{array}{l}\text { Sample } \\
\text { code }\end{array}$ & HDI/mole & $\begin{array}{l}\text { PEG- } \\
\text { 2000/ } \\
\text { mole }\end{array}$ & $\begin{array}{l}\text { BDO/ } \\
\text { mole }\end{array}$ & $\begin{array}{l}\text { Chitosan: } \\
\text { BDO/ } \\
\text { mass ratio }\end{array}$ & $\begin{array}{l}\text { HAp/ } \\
\text { mass\% }\end{array}$ \\
\hline PU1 & 3 & 2 & 1 & $0: 1$ & - \\
PU2 & 3 & 2 & 1 & $0.1: 0.9$ & - \\
PU3 & 3 & 2 & 1 & $0.25: 0.75$ & - \\
PU4 & 3 & 2 & 1 & $0.5: 0.5$ & - \\
PU5 & 3 & 2 & 1 & $1: 0$ & - \\
PU6 & 3 & 2 & 1 & $0.25: 0.75$ & 1 \\
PU7 & 3 & 2 & 1 & $0.25: 0.75$ & 5 \\
PU8 & 3 & 2 & 1 & $0.25: 0.75$ & 10 \\
PU9 & 3 & 2 & 1 & $0.25: 0.75$ & 15 \\
\hline
\end{tabular}


Fig. 1 SEM microphotographs of PU modified with chitosan and HAp and the results of EDX analysis: a PU1, b PU6, c PU7, d PU8 (average analysis), e PU1 (EDX analysis at point 2), f PU6 (EDX analysis at point 2)
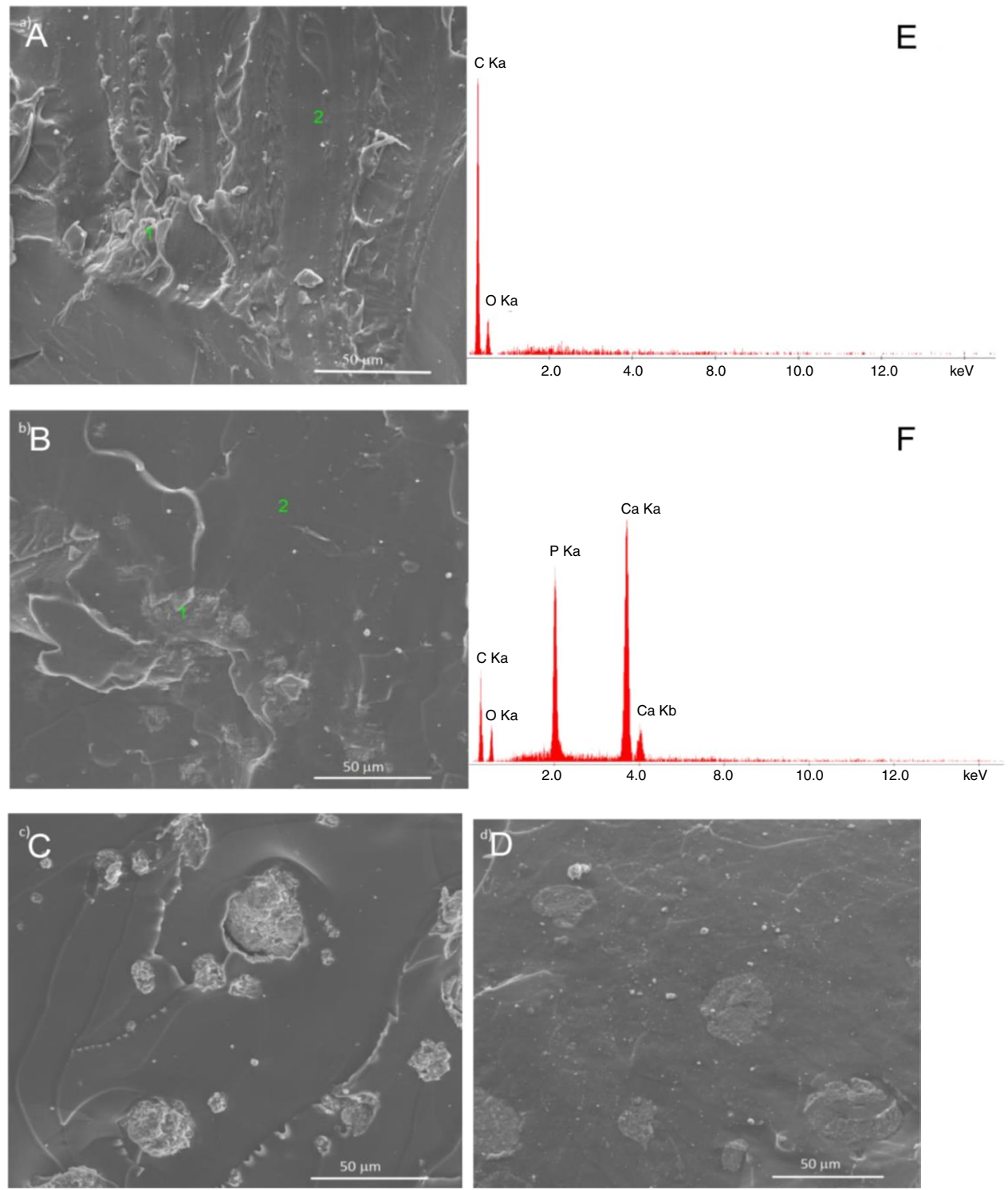

software. Multi-frequency temperature-modulated differential scanning calorimetry (TOPEM ${ }^{\circledR}$ DSC) measurements were carried out at a $10 \mathrm{~K} \mathrm{~min}^{-1}$ heating rate, \pm 0.5 modulation amplitude, $K$ switching time within the 15-30 s range and under a nitrogen atmosphere. The measurement was composed of two heating runs, with the first one to remove the thermal history. An indium standard was employed for calibration.

\section{Results and discussion}

SEM microphotographs of the PU/chitosan composites with increasing HAp content are presented in Fig. 1.
The results show that the HAp content strongly affects the surface morphology of PU. At higher HAp content (Fig. 1c, d), HAp undergoes agglomeration but, generally, the quality of HAp dispersion is good. The progressive growth of HAp domains allowed the polymer chains to re-organize to long-range ordering. In this case, cohesive interactions appeared between the HAp particles and between the polymer chains and HAp particles [19]. The results of the semiquantitative analysis of the HAp content in the composite matrix by EDS showed that the material contains a mineral phase and organic matrix. The crystals of HAp are visible as bright points, which are composed of $\mathrm{Ca}$ and $\mathrm{P}$. The analysis indicated that the dark area is a polymer organic phase built mainly from carbon and oxide atoms. 

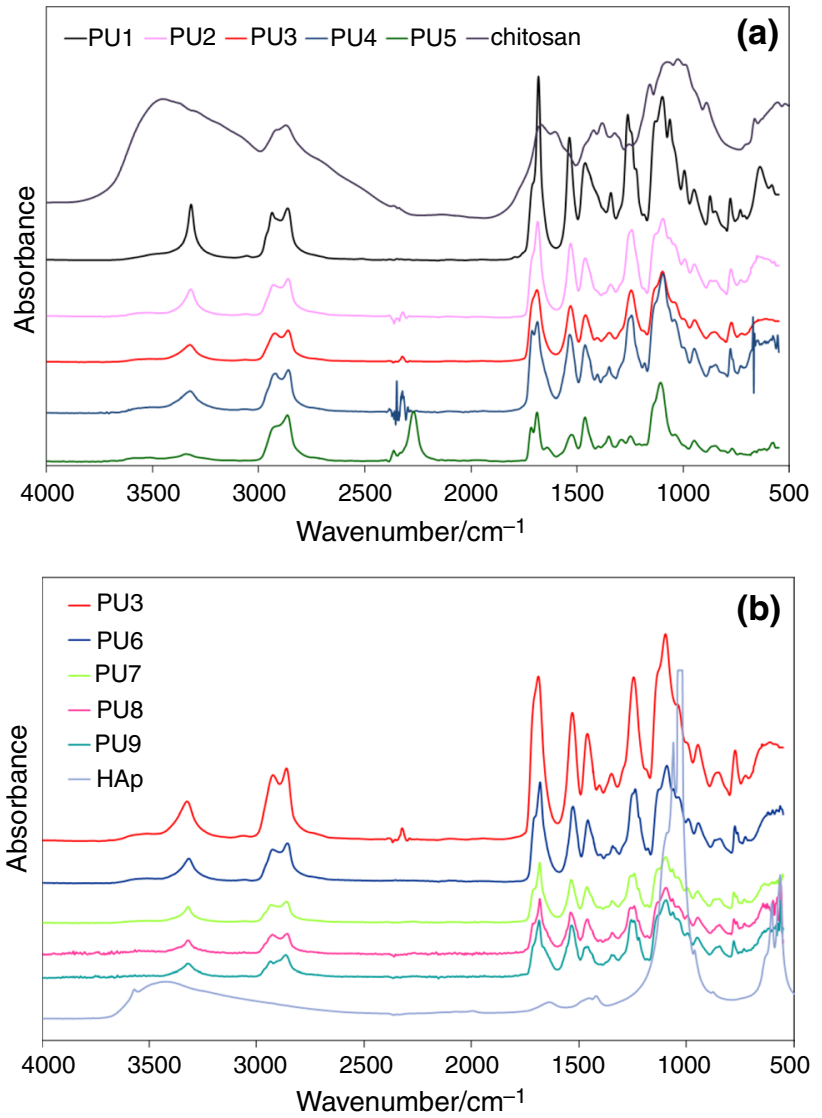

Fig. 2 FTIR spectra of PU materials crosslinked using chitosan (a), chitosan and/or HAp (b)

The chemical structure of PU/chitosan/HAp composites was confirmed using FTIR spectroscopy. The FTIR spectra are presented in Fig. 2, and data are collected in Table 2.

In the PU IR spectra, one can observe the absorption bands associated with a urethane group, such as the
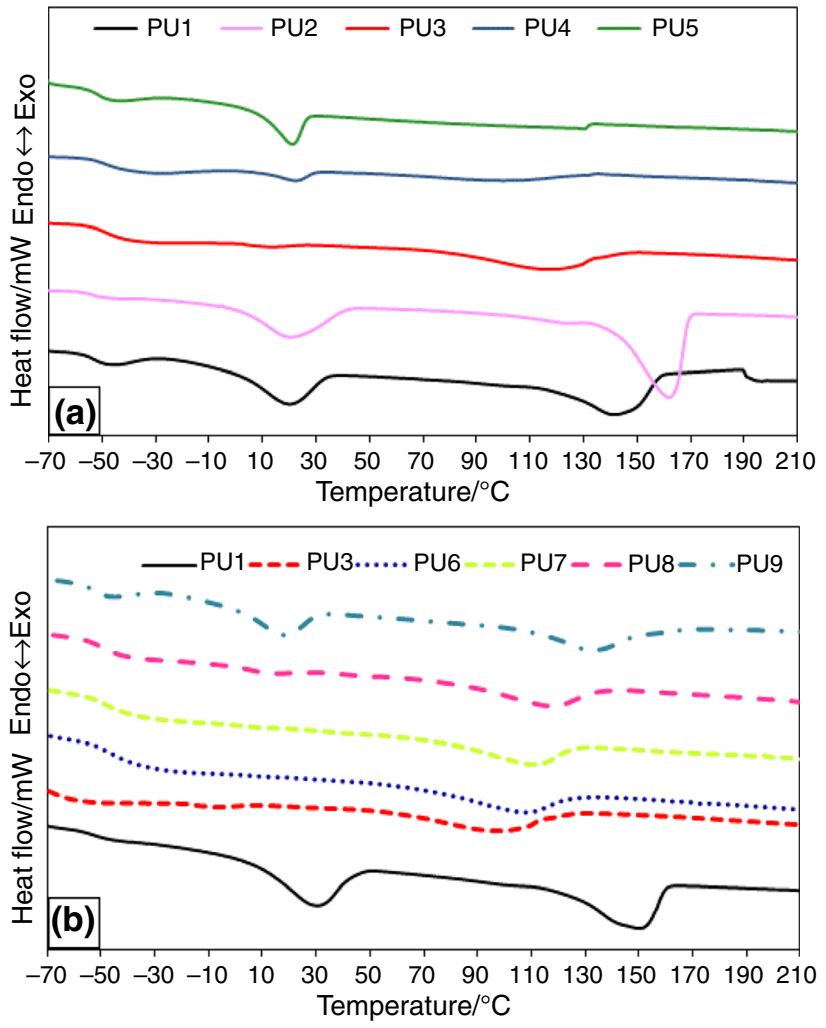

Fig. 3 DSC profiles of PU/chitosan (a) and PU/chitosan/hydroxyapatite composites (b)

stretching vibrations of an amine group $-\mathrm{NH}$ at $3300 \mathrm{~cm}^{-1}$ [20]. The position of bands suggests that $-\mathrm{NH}$ groups are engaged in the formation of hydrogen bonds [21]. The double peak appearing at ca. 1712 and $1680 \mathrm{~cm}^{-1}$ can be attributed to stretching vibrations of $\mathrm{C}=\mathrm{O}$ in urethane groups engaged in hydrogen bond formation. These results suggest phase separation in the PU matrix. The peak at
Table 2 Interpretation of the FTIR spectra of PU materials crosslinked using chitosan and/ or HAp

\begin{tabular}{llllllllllll}
\hline PU1 & PU2 & PU3 & PU4 & PU5 & PU6 & PU7 & PU8 & PU9 & HAp & Chitosan & \\
\hline- & - & - & - & - & - & - & - & - & 3569 & - & O-H stretching (HAp) \\
3318 & 3320 & 3324 & 3323 & 3342 & 3320 & 3319 & 3319 & 3320 & - & - & N-H stretching \\
2936 & 2930 & 2924 & 2920 & - & 2930 & 2933 & 2926 & 2936 & - & - & $\mathrm{CH}_{2}$ asymmetric \\
2863 & 2861 & 2861 & 2860 & 2865 & 2861 & 2861 & 2857 & 2864 & - & 2873 & $\mathrm{CH}_{2}$ symmetric stretching \\
- & 2321 & 2323 & 2324 & 2270 & - & - & - & - & - & 2338 & $\mathrm{C}=$ O stretching \\
1681 & 1685 & 1689 & 1687 & 1688 & 1685 & 1683 & 1682 & 1685 & - & 1668 & $\mathrm{~N}-\mathrm{H}$ stretching \\
1536 & 1530 & 1530 & 1534 & 1525 & 1532 & 1536 & 1538 & 1534 & - & - & $\mathrm{N}-\mathrm{H}$ deformation \\
- & - & 1405 & 1404 & 1399 & - & - & - & - & & 1380 & $\mathrm{C}-\mathrm{N}$ stretching \\
1098 & 1096 & 1097 & 1095 & 1106 & 1095 & 1096 & 1095 & 1094 & - & 1157 & $\mathrm{PO}_{4}{ }^{3-}$ \\
730 & 728 & 724 & 729 & 730 & 729 & 730 & 729 & 731 & 602 & - & $\mathrm{O}_{-H}$ (HAp) \\
- & - & - & - & - & 567 & 551 & 559 & 561 & 562 & - & $\mathrm{PO}_{4}{ }^{3-}$ \\
\hline
\end{tabular}


Table 3 DSC and TOPEM DSC results for PU/chitosan/HAp samples

\begin{tabular}{|c|c|c|c|c|c|c|c|c|c|c|c|}
\hline \multirow[t]{3}{*}{ Sample } & \multicolumn{4}{|c|}{ Glass transition of soft segments } & \multicolumn{2}{|c|}{$\begin{array}{l}\text { Melting of soft } \\
\text { segments }\end{array}$} & \multicolumn{2}{|c|}{$\begin{array}{l}\text { Glass transition of } \\
\text { hard segments }\end{array}$} & \multicolumn{3}{|c|}{ Melting of hard segments } \\
\hline & DSC & DSC & TOPEM DSC & TOPEM DSC & DSC & DSC & DSC & DSC & DSC & DSC & TOPEM DSC \\
\hline & $T_{\mathrm{g}} /{ }^{\circ} \mathrm{C}$ & $\Delta C_{\mathrm{p}} / \mathrm{J} \mathrm{g}^{-1}$ & $T_{\mathrm{g}} /{ }^{\circ} \mathrm{C}$ & $\Delta C_{\mathrm{p}} / \mathrm{J} \mathrm{g}^{-1}$ & $T_{\mathrm{m}} /{ }^{\circ} \mathrm{C}$ & $\Delta H / \mathrm{J} \mathrm{g}^{-1}$ & $T_{\mathrm{g}} /{ }^{\circ} \mathrm{C}$ & $\Delta C_{\mathrm{p}} / \mathrm{J} \mathrm{g}^{-1}$ & $T_{\mathrm{m}} /{ }^{\circ} \mathrm{C}$ & $\Delta H / \mathrm{J} \mathrm{g}^{-1}$ & $T_{\mathrm{m}} /{ }^{\circ} \mathrm{C}$ \\
\hline PU1 & -57 & 0.070 & -50 & 0.483 & 20 & 22.2 & -2 & 0.460 & 142 & 33.3 & 123 \\
\hline PU2 & -52 & 0.169 & -54 & 0.222 & 13 & 0.45 & - & - & 161 & 46.8 & \\
\hline PU3 & -46 & 0.444 & -47 & 0.380 & - & - & - & - & 116 & 18.7 & 132 \\
\hline PU4 & -44 & 0.465 & -48 & 0.398 & 22 & 3.1 & - & - & 99 & 10.4 & 113 \\
\hline PU5 & -53 & 0.200 & -54 & 0.190 & 21 & 11.1 & 4 & 0.325 & - & - & - \\
\hline PU6 & -42 & 0.680 & -43 & 0.439 & - & - & -7 & 0.040 & 107 & 78.6 & 107 \\
\hline PU7 & -46 & 0.462 & -46 & 0.422 & - & - & -4 & 0.020 & 112 & 68.9 & 116 \\
\hline PU8 & -49 & 0.420 & -43 & 0.440 & - & - & -6 & 0.040 & 118 & 71.5 & 107 \\
\hline PU9 & -52 & 0.337 & -53 & 0.174 & 17 & 15.8 & - & - & 132 & 17.3 & - \\
\hline
\end{tabular}
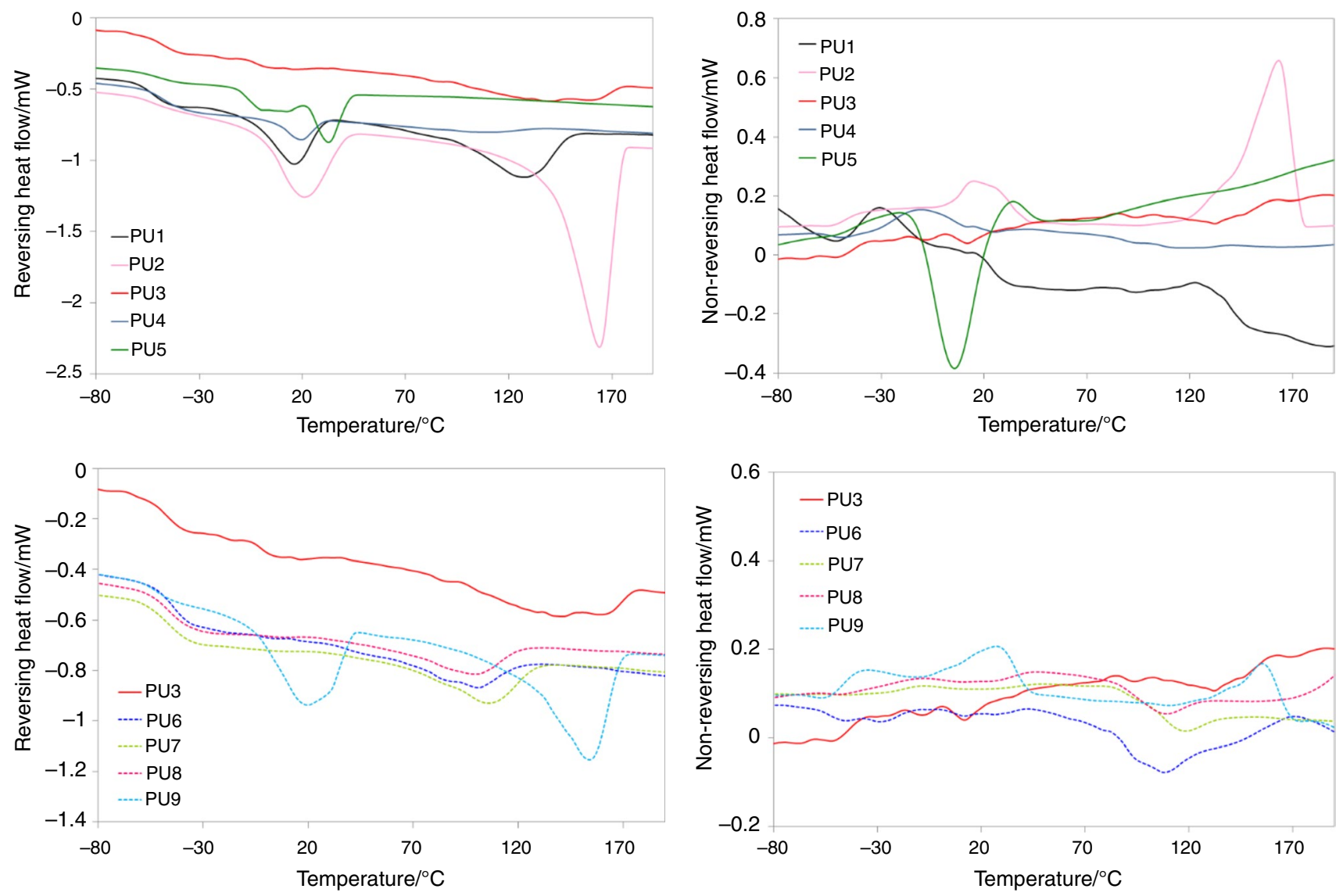

Fig. 4 TOPEM DSC curves of PU/chitosan and PU/chitosan/hydroxyapatite systems 

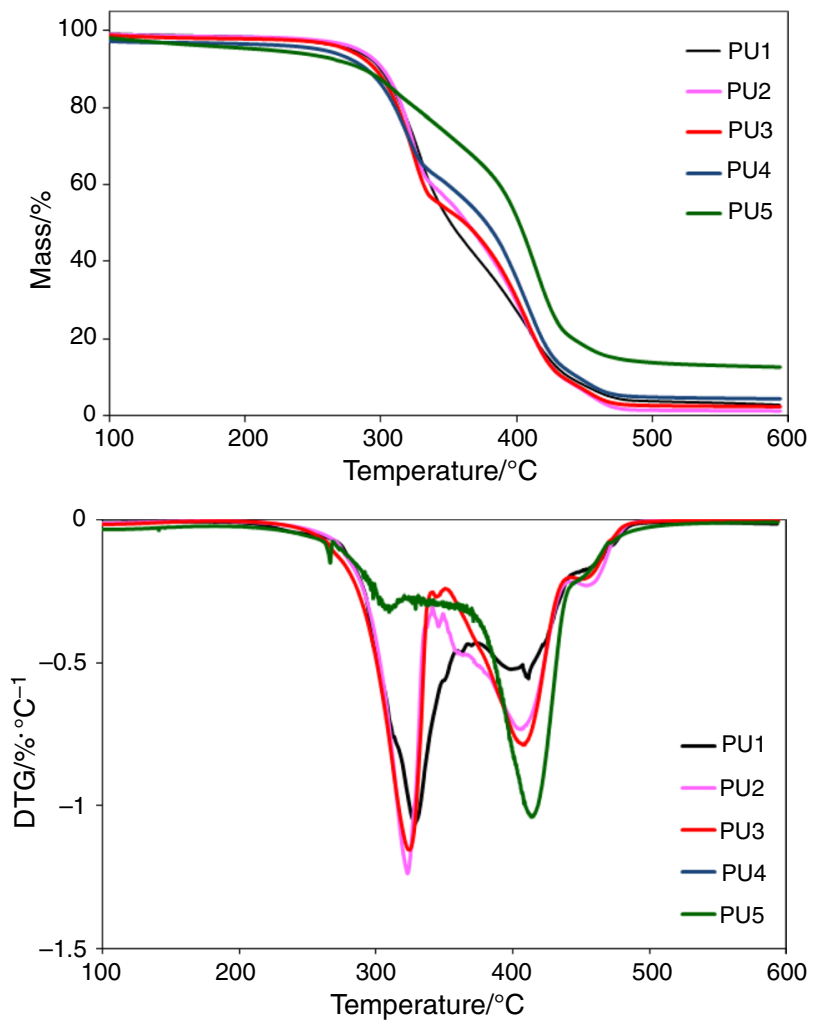

Fig. 5 TG and DTG curves of PU/chitosan composites

$1530 \mathrm{~cm}^{-1}$, representing $\mathrm{N}-\mathrm{H}$ deformations, indicates II amide bands, and the bands at $1240 \mathrm{~cm}^{-1}$ represent $\mathrm{C}-\mathrm{N}$ stretching of III amide [22]. In the FTIR spectrum of the PU samples, the absorption band at $2249 \mathrm{~cm}^{-1}$, associated with the stretching vibration of the valence -NCO groups, is not observed, which confirms the complete polymerization of diisocyanates at the synthesis stage [23]. Absorption bands for $\mathrm{CH}_{2}$ asymmetric and $\mathrm{CH}_{2}$ symmetric stretching are visible at $2930 \mathrm{~cm}^{-1}$ and $2860 \mathrm{~cm}^{-1}$, respectively. There are other bands in the range of $1036-1098 \mathrm{~cm}^{-1}$ which can be attributed to the vibration of the $\mathrm{PO}_{4}^{3-}$ group. The peak at $560 \mathrm{~cm}^{-1}$ is assigned to vibrations of $\mathrm{PO}_{4}^{3-}$ in the structure of hydroxyapatite. Moreover, no absorption bands from -OH groups in HAp can be found that suggest covalent bonding of HAp to PU matrix. Also, no absorption bands from $-\mathrm{OH}$ groups in the chitosan structure have been found that confirm chemical bonding of chitosan to PU.

In order to choose the appropriate ratio of BDO and chitosan as crosslinkers for PUs, DSC analysis was performed-Fig. 3 and Table 3.

It was observed that $T_{\mathrm{g}}$ increases with an increase of chitosan load: $-46.8{ }^{\circ} \mathrm{C},-43.1{ }^{\circ} \mathrm{C}$ and $-41.0{ }^{\circ} \mathrm{C}$ for 10,25 and 50\% chitosan, respectively. The $T_{\mathrm{g}}$ increase is caused by the formation of intermolecular hydrogen bonding between PU chains and chitosan, which was confirmed in the FTIR
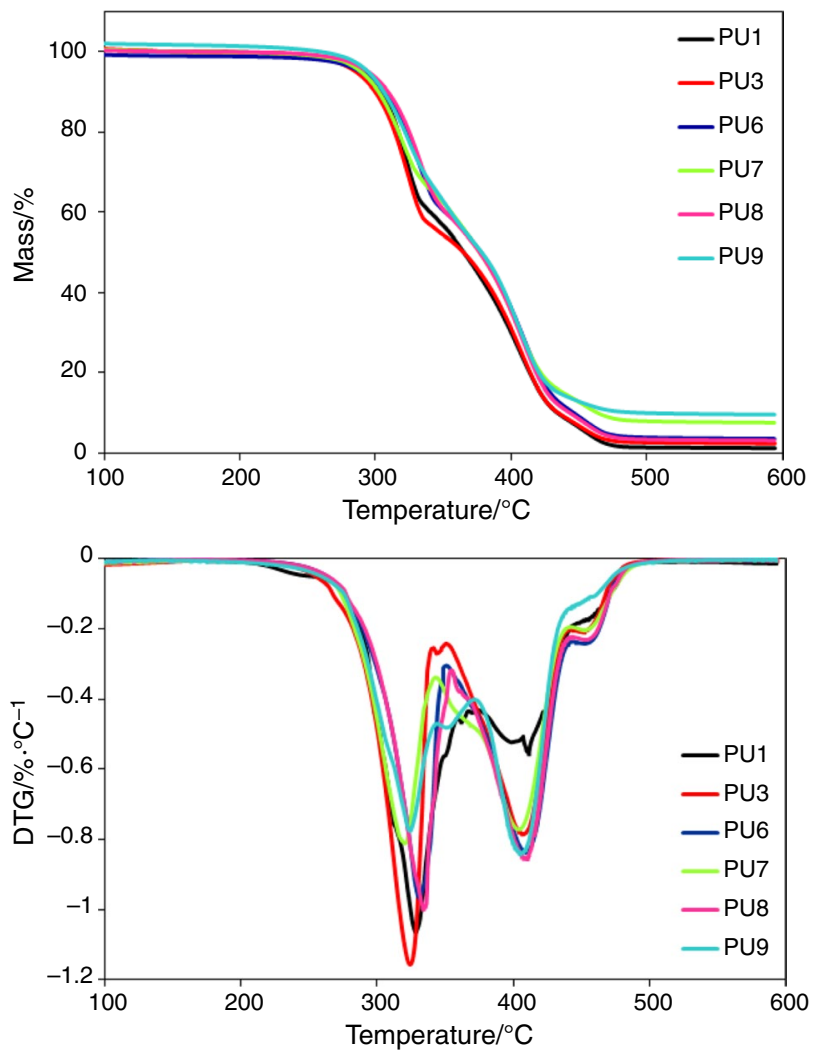

Fig. 6 TG and DTG curves of PU/chitosan/hydroxyapatite composites

analysis [24]. The effect observed for $C_{\mathrm{p}}$ is similar, apart from the sample with $100 \%$ chitosan and $T_{\mathrm{g}}$ of $-53.2{ }^{\circ} \mathrm{C}$, which is close to that of PU crosslinked with BDO only $\left(-56.5^{\circ} \mathrm{C}\right)$. The melting temperature $\left(T_{\mathrm{m}}\right)$ is responsible for the breakdown of aggregate structures, like the crystalline phase, sustained by intermolecular forces. A lower $T_{\mathrm{m}}$ of hard segments for chitosan-based PU than for unmodified PU proved less participation of the three-dimensional structure after incorporation of polysaccharides. This effect might also be generated by the molecular segmental motion of the amorphous structure. For chitosan-based PU with HAp (Table 3), increasing the content of HAp from 1 to $10 \%$ led to a $10{ }^{\circ} \mathrm{C}$ increase in $T_{\mathrm{m}}$. This result is probably connected to the presence of hydroxyapatite that can act as a nucleating agent for PU chains. Due to the complex thermal behaviour of the obtained composites, TOPEM DSC (Fig. 4) measurements were performed to confirm that the endothermic peak at the temperature over $100{ }^{\circ} \mathrm{C}$ is due to the melting of hard segments. As can be seen in the temperature range over $100{ }^{\circ} \mathrm{C}$, a signal that is typical for melting is observed on both reversing and non-reversing heat flow profiles.

On the DSC curves, an endothermic peak at ca. $20-30{ }^{\circ} \mathrm{C}$ for samples cured with chitosan has been observed. However, changes in the position of baseline after phase 
Table 4 TG results of PU/ chitosan/HAp composites

\begin{tabular}{lllllll}
\hline Sample & $T_{1 \%} /{ }^{\circ} \mathrm{C}$ & $T_{3 \%} /{ }^{\circ} \mathrm{C}$ & $T_{5 \%} /{ }^{\circ} \mathrm{C}$ & $T_{10 \%} /{ }^{\circ} \mathrm{C}$ & $T_{50 \%} /{ }^{\circ} \mathrm{C}$ & $T_{\text {DTGmax }} /{ }^{\circ} \mathrm{C}$ \\
\hline PU1 & 233 & 271 & 287 & 302 & 353 & $330,410,439$ \\
PU2 & 252 & 280 & 291 & 304 & 365 & $342,405,453$ \\
PU3 & 250 & 274 & 285 & 300 & 365 & $324,408,453$ \\
PU4 & 238 & 268 & 281 & 297 & 381 & $319,407,437$ \\
PU5 & 199 & 252 & 275 & 302 & 404 & $410,439,442$ \\
PU6 & 222 & 274 & 289 & 306 & 378 & $329,409,454$ \\
PU7 & 252 & 280 & 290 & 302 & 377 & $321,404,454$ \\
PU8 & 259 & 284 & 294 & 309 & 377 & $334,415,453$ \\
PU9 & 177 & 267 & 294 & 306 & 378 & $324,406,457$ \\
\hline
\end{tabular}

transition can be observed that suggest glass transition with relaxation effect, but in the same temperature region melting of soft segments is also possible. From TOPEM DSC results, it can be seen that for PU1, PU2 and PU5, only melting of soft segments can be found, while for PU3, only glass transition of hard segments. For PU5, both glass transition of hard segments and melting with recrystallization of soft segments were detected. For PU additionally modified with HAp, glass transition of hard segments without melting of soft segments can be seen. Only for PU9 melting of soft segments was found. Soft segment ability to crystallize is linked with restrictions of chain movements and crosslinking density $[25,26]$. It seems that replacement of $25 \%$ BDO with chitosan leads to formation of the most rigid structure with limited crystallization ability and for such a structure only glass transition can occur.

The thermogravimetric data show that the obtained PUs degrade in a three-stage process-Figs. 5 and 6, Table 4.

The first step with $T_{\text {DTGmax }}=330{ }^{\circ} \mathrm{C}$ arises from the degradation of hard segments with the break of urethane bonds; isocyanates, polyols, primary and secondary amines and carbon dioxide are formed [27]. The second step results from the decomposition of poly(ethylene glycol) used as a soft segment, with $T_{\text {DTGmax }}=410^{\circ} \mathrm{C}$. For unmodified PEG under non-oxidative conditions, $\mathrm{T}_{\text {DTGmax }}$ was detected at ca. $400{ }^{\circ} \mathrm{C}$. As the main volatile products of thermal degradation ethanol, methanol, alkenes, non-cyclic ethers, formaldehyde, acetic aldehyde, ethylene oxide, water, $\mathrm{CO}$ and also $\mathrm{CO}_{2}$ were identified [28]. The third and last step of PU composite degradation is connected to the degradation of residues [29]. Next, the effect of BDO/chitosan ratio on the thermal stability was investigated. PUs were obtained with five different ratios of BDO and chitosan. The crosslinking with 0.1 and 0.25 equivalent chitosan leads to an increase in the thermal stability, in comparison with unmodified PU, from 233 to $252{ }^{\circ} \mathrm{C}$ and $250{ }^{\circ} \mathrm{C}$, respectively. In addition, the effect of HAp on the thermal stability was studied. As shown in Table 4, the incorporation of HAp had practically no influence on the initial degradation temperature of PU compared to PU3. Only for PU8, where $10 \%$ of HAp has been incorporated, an increase in the thermal stability from 250 to $259{ }^{\circ} \mathrm{C}$ was observed. The incorporation of clays and inorganic material (e.g. hydroxyapatite) to the polymer matrix causes an increase in the thermal stability due to socalled labyrinth effect, hindering the transfer of volatiles produced during thermal decomposition [30].

\section{Conclusions}

In this work, two series of PU materials were examined. The first series is PUs crosslinked with a different molar ratio of chitosan and BDO. The second group are PUs crosslinked with chitosan and BDO with a variable mass fraction of hydroxyapatite. The FTIR study confirms the conversion of chitosan and HAp in reaction with the isocyanate group of the prepolymer. The SEM-EDAX analysis indicates that with increasing concentration of HAp the aggregates of ceramic additive become larger, and HAp is homogeneously distributed in the PU matrix. Based on TG results, the thermal stability of chitosan-based PUs increases with increasing fraction of polysaccharide from 233 to $252{ }^{\circ} \mathrm{C}$ and the addition of HAp has no significant influence on the initial degradation temperature. DSC showed that the glass transition temperature increase with chitosan load is caused by the formation of intermolecular hydrogen bonding between PU and polysaccharide macrochains. TOPEM DSC data revealed that the endothermic peak at the temperatures over $100{ }^{\circ} \mathrm{C}$ is due to the melting of hard segments. The obtained PU/chitosan/hydroxyapatite composites are promising materials for the replacement of acrylate bone cement, provided that further studies on biocompatibility are performed-such studies are in progress.

Acknowledgements The authors are grateful to the Polish National Science Centre for financial support under the Contract No. UMO2016/22/E/ST8/00048. MSz has been partly supported by the EU Project POWR.03.02.00-00-I004/16. 
Open Access This article is licensed under a Creative Commons Attribution 4.0 International License, which permits use, sharing, adaptation, distribution and reproduction in any medium or format, as long as you give appropriate credit to the original author(s) and the source, provide a link to the Creative Commons licence, and indicate if changes were made. The images or other third party material in this article are included in the article's Creative Commons licence, unless indicated otherwise in a credit line to the material. If material is not included in the article's Creative Commons licence and your intended use is not permitted by statutory regulation or exceeds the permitted use, you will need to obtain permission directly from the copyright holder. To view a copy of this licence, visit http://creativecommons.org/licenses/by/4.0/.

\section{References}

1. Chen Q, Liang S, Thouas GA. Elastomeric biomaterials for tissue engineering. Prog Polym Sci. 2013;38(3):584-671.

2. Król P. Synthesis methods, chemical structures and phase structures of linear polyurethanes. Properties and applications of linear polyurethanes in polyurethane elastomers, copolymers and ionomers. Prog Mater Sci. 2007;52(6):915-1015.

3. Cakić SM, Špírková M, Ristić IS, B-Simendić JK, M-Cincović $\mathrm{M}$, Poręba R. The waterborne polyurethane dispersions based on polycarbonate diol: effect of ionic content. Mater Chem Phys. 2013;138(1):277-85.

4. Kumagai S, Motokucho S, Yabuki R, Anzai A, Kameda T, Watanabe A, et al. Effects of hard- and soft-segment composition on pyrolysis characteristics of MDI, BD, and PTMG-based polyurethane elastomers. J Anal Appl Pyrol. 2017;126:337-45.

5. Somdee P, Lassú-Kuknyó T, Kónya C, Szabó T, Marossy K. Thermal analysis of polyurethane elastomers matrix with different chain extender contents for thermal conductive application. J Therm Anal Calorim. 2019;138(2):1003-10.

6. Xue Y, Sant V, Phillippi J, Sant S. Biodegradable and biomimetic elastomeric scaffolds for tissue-engineered heart valves. Acta Biomater. 2017;48:2-19.

7. Zaharescu T, Marinescu V, Hebda E, Pielichowski K. Thermal stability of gamma-irradiated polyurethane/POSS hybrid materials. J Therm Anal Calorim. 2018;133(1):49-54.

8. Basha RY, Sampath Kumar TS, Doble M. Design of biocomposite materials for bone tissue regeneration. Mater Sci Eng C. 2015;57:452-63.

9. Saravanan S, Leena RS, Selvamurugan N. Chitosan based biocomposite scaffolds for bone tissue engineering. Int J Biol Macromol. 2016;93:1354-65.

10. Zia KM, Anjum S, Zuber M, Mujahid M, Jamil T. Synthesis and molecular characterization of chitosan based polyurethane elastomers using aromatic diisocyanate. Int J Biol Macromol. 2014;66:26-32.

11. Zia F, Zia KM, Zuber M, Rehman S, Tabasum S, Sultana S. Synthesis and characterization of chitosan/curcumin blends based polyurethanes. Int J Biol Macrom. 2016;92:1074-81.

12. Mahanta AK, Mittal V, Singh N, Dash D, Malik S, Kumar M, et al. Polyurethane-grafted chitosan as new biomaterials for controlled drug delivery. Macromolecules. 2015;48(8):2654-66.

13. Barikani M, Honarkar H, Barikani M. Synthesis and characterization of chitosan-based polyurethane elastomer dispersions. Chem Mon. 2010;141(6):653-9.

14. Barikani M, Honarkar H, Barikani M. Synthesis and characterization of polyurethane elastomers based on chitosan and poly $(\varepsilon-$ caprolactone). J Appl Polym Sci. 2009;112(5):3157-65.
15. Tsiourvas D, Sapalidis A, Papadopoulos T. Hydroxyapatite/ chitosan-based porous three-dimensional scaffolds with complex geometries. Mater Today Commun. 2016;7:59-66.

16. Zhou H, Lee J. Nanoscale hydroxyapatite particles for bone tissue engineering. Acta Biomater. 2011;7(7):2769-81.

17. Pielichowska K, Blazewicz S. Bioactive polymer/hydroxyapatite (nano)composites for bone tissue regeneration. In: Abe A, Dusek K, Kobayashi S, editors. Biopolymers, vol. 232., Advances in polymer scienceBerlin: Springer; 2010. p. 97-207.

18. Pielichowska K, Krol K, Majka TM. Polyoxymethylene-copolymer based composites with PEG-grafted hydroxyapatite with improved thermal stability. Thermochim Acta. 2016;633:98-107.

19. Ribeiro CA, Martins MVS, Bressiani AH, Bressiani JC, Leyva ME, de Queiroz AAA. Electrochemical preparation and characterization of PNIPAM-HAp scaffolds for bone tissue engineering. Mater Sci Eng C. 2017;81:156-66.

20. Fuensanta M, Jofre-Reche JA, Rodríguez-Llansola F, Costa V, Iglesias JI, Martín-Martínez JM. Structural characterization of polyurethane ureas and waterborne polyurethane urea dispersions made with mixtures of polyester polyol and polycarbonate diol. Prog Organ Coat. 2017;112:141-52.

21. Güney A, Hasirci N. Properties and phase segregation of crosslinked PCL-based polyurethanes. J Appl Polym Sci. 2014; 131(1):39758.

22. Król P, Pilch-Pitera B. Urethane oligomers as raw materials and intermediates for polyurethane elastomers. Methods for synthesis, structural studies and analysis of chemical composition. Polymer. 2003;44(18):5075-101.

23. Javaid MA, Khera RA, Zia KM, Saito K, Bhatti IA, Asghar M. Synthesis and characterization of chitosan modified polyurethane bio-nanocomposites with biomedical potential. Int J Biol Macromol. 2018;115:375-84.

24. Indumathi MP, Rajarajeswari GR. Mahua oil-based polyurethane/ chitosan/nano $\mathrm{ZnO}$ composite films for biodegradable food packaging applications. Int J Biol Macromol. 2019;124:163-74.

25. Li Y, Duan L, Cheng L, Yang Y, Li Y, Cheng Y, et al. Thermal analysis and crystallization kinetics of polyurethane. J Therm Anal Calorim. 2019;135(5):2843-8.

26. Kong W, Lei Y, Jiang Y, Lei J. Preparation and thermal performance of polyurethane/PEG as novel form-stable phase change materials for thermal energy storage. J Therm Anal Calorim. 2017;130(2):1011-9.

27. Jiao L, Xiao H, Wang Q, Sun J. Thermal degradation characteristics of rigid polyurethane foam and the volatile products analysis with TG-FTIR-MS. Polym Degrad Stab. 2013;98(12):2687-96.

28. Pielichowski K, Flejtuch K. Non-oxidative thermal degradation of poly(ethylene oxide): kinetic and thermoanalytical study. J Anal Appl Pyrol. 2005;73(1):131-8.

29. Lewicki JP, Pielichowski K, De La Croix PT, Janowski B, Todd D, Liggat JJ. Thermal degradation studies of polyurethane/POSS nanohybrid elastomers. Polym Degrad Stab. 2010;95(6):1099-105.

30. Berta M, Lindsay C, Pans G, Camino G. Effect of chemical structure on combustion and thermal behaviour of polyurethane elastomer layered silicate nanocomposites. Polym Degrad Stab. 2006;91(5):1179-91.

Publisher's Note Springer Nature remains neutral with regard to jurisdictional claims in published maps and institutional affiliations. 